is expected that if this tax policy is launched and successful, a tradition and culture will soon be established in Vietnamese society, in which donors of not-for profit private universities will no longer request to get financial returns on their donations.

\section{The Crucial Presence of Private Higher Education in Latin America}

\section{Dante J. Salto}

Dante J. Salto is a postdoctoral fellow at the Universidad Nacional de Cordoba (Argentina) and affiliate at the Program for Research on Private Higher Education (PROPHE), University at Albany. E-mail: dantesalto@gmail.com. (IHE regularly publishes articles from PROPHE, see http://www.albany.edu/ prophe.).

$\mathrm{O}$ n March 4-7, 2016, leading Latin American higher education scholars and practitioners held a "summit" meeting to reflect on key developments and trends in their field. Private higher education (PHE) was not the sole focus of the conference, but became the topic of many meaningful discussions. This article reports on PHE and closely related issues, such as privatization and the comparison between the public and private sectors, highlighted at the summit.

A central reality, repeatedly emphasized during the conference, is that any serious and comprehensive discussion on important developments in Latin American higher education and related policy must perforce deal with PHE. This reality is not surprising, given the fact that over 40 percent of Latin American higher education enrollment is in the private sector (PROPHE data). The crucial role of PHE was shown in a variety of issues, including quality, access, expansion, equity, regulatory policy (including accreditation), new public management, academic and reputational rankings, corruption, and more.

\section{Integral to Regional Development}

Many of the historical developments and trends addressed during the summit related to the expansion of the region's higher education systems, and the resulting diversification of both public and private sectors. One keynote speaker, World Bank's Lead Tertiary Education Specialist and Coordinator Francisco Marmolejo, pointed to challenges facing the region's higher education based on an expanding "demographic window," in which working-age adults increasingly access higher education. Demand for higher education nowadays comes not just from youth reaching conventional higher education age, but also from nontraditional students-a population not given much consideration until now by public and private institutions. This nontraditional population is increasingly targeted by alternative private institutions - not necessarily university-level, or degree-granting — as well as by some recently created public institutions. Thus, the private sector plays, and will continue to play, a critical and evolving role in absorbing demand not satisfied through traditional institutions.

Diversification of higher education presents challenges to regulatory policies such as quality assurance. A recent but widespread occurrence in Latin American countries, formal quality assurance systems have usually relied on a single, "optimal" institutional model aligned on a country's most prestigious public universities. Accommodating to the variety of new institutional missions is an ongoing challenge for quality assurance systems, a challenge exacerbated by the rise of new private forms of education.

Presentations further highlighted that diversification and privatization relate to more than just the growth of PHE. Market-friendly reforms have pushed the region's public institutions toward increased internal privatization. Following a global trend, public institutions employ a variety of strategies to privatize. Revenue generation plays a major role and is often controversial. Public universities progressively seek external funding and establish public-private partnerships, gradually abandoning their longstanding reliance on the state as sole source of finance and responsibility. Similarly, panelists illustrated how public university adaptation of private sector governance practices, translated as public management reforms, has led to new blurriness in the public-private divide. Some speakers wondered to what extent these trends may signal that public universities are becoming entrepreneurial, as they seek to adapt to a changing environment.

\section{Traditional vs. New and Evolving Forms of Privatization}

Latin American PHE issues vary from longstanding to emerging ones, in most cases driven by contextual factors such as demographic changes or political and economic trends. Scholarship exploring historical developments and current trends emphasizes how the private sector has changed over time. Some research focuses on how public policies have overlooked, or even inhibited, the expansion of the private sector, whereas other work depicts public policy as promoting PHE. Remarkably, with borders between sectors becoming increasingly blurred, private institutions 
are more boldly proclaiming their fulfillment of public purposes, such as meeting government access targets.

Of course, enrollment growth to meet access targetsa dominant topic in Latin American policy discussion for more than half a century-has for much of that same time period drawn attention to PHE, as considerable expansion has been achieved through private provision. But the summit focused on the present moment, exploring how this growth increasingly occurs in new and evolving forms of PHE. Several countries in the region now allow legally for-profit institutions. This break with tradition and traditional norms has naturally provoked controversy. The most noteworthy for-profit occurrence takes place in the region's largest higher education system (by absolute enrollment), Brazil. Brazil has not only allowed for-profits, but also financially incentivized them to provide access for needy students. Other countries participating in the for-profit trend are Peru, Bolivia, and Chile (only nonuniversity).

\section{A central reality, repeatedly emphasized during the conference, is that any seri- ous and comprehensive discussion on important developments in Latin Ameri- can higher education and related policy must perforce deal with PHE.}

Though not as dramatic as for-profit growth, various aspects of "Americanized" managerialism help reshape Latin American higher education. It has long been noted that such managerialism has thrived in the region's PHE. For example, private universities tend to hire managerial professionals rather than just asking academics to serve as managers. But, conference participants also provided examples of increased managerialism in public institutions, notably in some of the newer ones. Similarly, now even public universities are involving more external actors in their governance structures. This is portrayed as a shift toward increased accountability to various external stakeholders and perhaps the general citizenry. Such documented tendencies in the public sector further blur traditional divides between private and public higher education.

\section{Ongoing Research on Private Higher Education}

Finally, the summit took note of major efforts to study Latin America's evolving PHE and related private-public matters. Regional agencies, consortia, and research centers all play identifiable roles. Coordinated by summit-participant José Joaquín Brunner, the Centro Interuniversitario de Desarrollo (CINDA) publishes reports on current issues in Latin American higher education incorporating sections on the role of the private sector. The Inter-American Development Bank is reediting a policy report on PHE in Latin America. The Center for International Higher Education at Boston College is involved in a project on the internationalization of Catholic universities. PROPHE continues its research on Latin American PHE in a global context.

Whatever the future knowledge generated by ongoing research efforts, the summit's scholars and policymakers grappled with knowledge already at hand. All in all, as they addressed many of the salient issues in Latin American higher education, they repeatedly noted how PHE and related privatization realities, some longstanding, some new, illustrate beyond doubt how important and integral private higher education is to those overall developments.

\section{Revenue Diversification and Reform in Ethiopian Higher Education}

\section{Kibrome Mengistu Feleke}

Kibrome Mengistu Feleke is a lecturer and researcher at the Department of Psychology, Bahir Dar University, Ethiopia. He holds a Master degree in Administrative Science in Higher Education. E-mail: kbmen1973@yahoo.com.

$\mathbf{S}$ ome twenty years ago, the Ethiopian higher education system was generally characterized as very limited in access, inequitable, poor in quality, weak in research output, and underfunded. In order to ensure access, equity, quality, relevance, and efficiency, the Ethiopian government has since I994 introduced major reforms and policy changes to the higher education sector.

Following the reforms, the system has expanded massively within the past two decades, from only two to 36 public universities today. Private higher education has also flourished since I997, with 98 institutions accommodating around is percent of the total enrollment. This rapid expansion has increased undergraduate enrollment from about 35,000 students in 1996 to 593,57I in 2014. Hence, higher education enrollment has grown from 0.8 percent in 1996 to 9.4 percent in 2014 .

In general, heavy government investment on higher 